\title{
Preliminary Study of the Applicability of Software in the Investigation of Sustained Auditory Attention
}

\author{
Mariza Ribeiro Feniman ${ }^{10}$ Maria Renata José2® Maria Fernanda Capoani Garcia Mondelli10

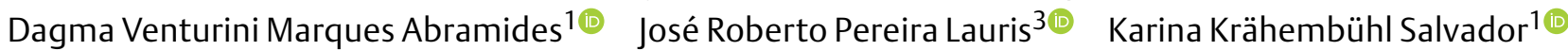 \\ Maria Gabriela Cavalheiro ${ }^{4}$ L Luciana Paula Maximino ${ }^{1,4}$
}

\footnotetext{
${ }^{1}$ Department of Speech Pathology and Audiology, Faculdade de Odontologia de Bauru, Universidade de São Paulo (FOB-USP), Bauru, SP, Brasil

2 Postgraduate Program in Communication Disorders, Universidade de Tuiuti do Paraná, Curitiba, PR, Brasil

3 Department of Pediatric Dentistry, Orthodontics and Public Health, Universidade de São Paulo (FOB-USP), Bauru, SP, Brasil

${ }^{4}$ Hospital for Rehabilitation of Craniofacial Anomalies, Universidade de São Paulo (HRAC-USP), Bauru, SP, Brasil
}

Address for correspondence Mariza Ribeiro Feniman, PhD, Departamento de Fonoaudiologia, Faculdade de Odontologia de Bauru, Universidade de São Paulo (FOB-USP), Alameda Dr. Octavio Pinheiro Brisolla 9-75-Vila Universitária, Cep: 17012-901, BAURU, SP, Brasil (e-mail: feniman@usp.br).

Int Arch Otorhinolaryngol 2022;26(3):e453-e459.

\begin{abstract}
Keywords

- attention

- children

- aptitude

- evaluation study

- software

Introduction The use of auditory behavioral tests, which specifically assess sustained attention, is necessary, due to its relationship with learning, language production, cognitive development and school performance.

Objective To evaluate how children performed using software developed to investigate the ability of sustained auditory attention, and to compare the scores obtained in this format with those of the original, non-computerized test.

Methods This cross-sectional study included 52 children of both genders, aged 6 to 11 years, with normal hearing and no history of complaints regarding inattention and/or hyperactivity. The computerized test was administered to all 52 children. The total error score (inattention and impulsivity) and the vigilance decrement were used to define the children's performance when using the software. The scores obtained in the two formats (computer software and original on compact disc) were then compared.

Results Statistically significant differences were found in the scores for innattention, impulsivity, and total error score (inattention and impulsivity) when comparing genders, and a negative correlation coefficient was found when comparing ages. Increased scores were found for all variables of the sustained auditory attention ability test (SAAAT) compared with the original format.

Conclusion Females performed worse than males in all aspects except for vigilance decrement when using the SAAAT software developed to evaluate the ability of SAAAT vigilance; younger children made more errors when using the SAAAT software; inattention errors were more frequent than impulsivity. Overall, higher values were obtained using the SAAAT software, when compared with the original version.
\end{abstract}

received

January 30, 2021 accepted after revision

August 29, 2021

published online

January 27,2022
DOI https://doi.org/ 10.1055/s-0041-1741029. ISSN 1809-9777. (c) 2022. Fundação Otorrinolaringologia. All rights reserved.

This is an open access article published by Thieme under the terms of the Creative Commons Attribution-NonDerivative-NonCommercial-License, permitting copying and reproduction so long as the original work is given appropriate credit. Contents may not be used for commercial purposes, or adapted, remixed, transformed or built upon. (https://creativecommons.org/ licenses/by-nc-nd/4.0/)

Thieme Revinter Publicações Ltda., Rua do Matoso 170, Rio de Janeiro, RJ, CEP 20270-135, Brazil 


\section{Introduction}

Considered a basic attention-related process, sustained attention refers to the ability to maintain concentrated attention over prolonged periods of time. ${ }^{1}$ Continuous performance testing (CPT), a measure which uses tasks of continuous performance, has provided the most information on this skill in a variety of clinical settings. Continuous performance testing are deceptively simple tasks designed to capture difficulties in maintaining attention. ${ }^{2}$ They require the subject to be vigilant and to react to the presence or absence of a target stimulus, and vigilance requires the detection of infrequent stimuli, which are presented under monotonous conditions. ${ }^{3}$ Thus, when attention declines and the subject fails to respond to the target stimulus, errors of omission (inattention) occur. Additionally, errors of commission (impulsivity) occur when a response is given to a stimulus that is not the target.

The use of these auditory behavioral tests, which specifically assess the cognitive skill of sustained attention, is necessary, given that sustained attention and the underlying activity of attention networks are necessary for all types of learning activities. ${ }^{4}$ In addition to being a necessary skill for language production, ${ }^{5}$ sustained attention is essential for healthy cognitive development ${ }^{6}$ and for basic daily activities, such as attending school. ${ }^{7}$ Thus, deficits in sustained attention and auditory vigilance can cause difficulties in concentration, and impaired development and learning. Therefore, researchers developed a behavioral instrument called the sustained auditory attention ability test (SAAAT), which can assist in the identification of children with attention-based hearing problems. ${ }^{8}$ The SAAAT, based on CPT, is a simple behavioral test, easy and quick to administer, which aims to evaluate a person's sustained auditory attention abilities. In its original format (compact disc recording), ${ }^{8}$ it was administered in different methods ${ }^{9}$ and in different clinical populations. ${ }^{10,11}$

Computer programs have been growing in such a way that they can now solve various types of problems in healthcare, such as in clinical analysis laboratories, or in the creation of medical records platforms, which aim to reduce the time to search for information about a particular patient. The number of tests and instruments designed for use in patient care processes is increasing, and these tests and instruments are being computerized to make them more accurate, faster, more attractive, more time-efficient, and cheaper, both in their application and their analysis. The present study aimed to evaluate how children performed using software developed to assess the ability of sustained auditory attention, and to compare the scores obtained from the SAAAT with those of the original, non-computerized test.

\section{Methods}

The present study was an observational, cross-sectional and quantitative study and was approved by the local research ethics committee, under the number CAAE-0160.0.224.00009 . The guardians of the children received informed consent
Table 1 Distribution of the number of children according to gender and age

\begin{tabular}{|l|l|l|l|}
\hline AGE (years) & GENDER & \\
\hline & MALE & FEMALE & TOTAL \\
\hline 6 & 02 & 08 & 10 \\
\hline 7 & 06 & 07 & 13 \\
\hline 8 & 08 & 05 & 13 \\
\hline 9 & 03 & 03 & 6 \\
\hline 10 & 04 & 01 & 5 \\
\hline 11 & 01 & 04 & 5 \\
\hline TOTAL & 24 & 28 & 52 \\
\hline
\end{tabular}

forms containing information about the study in a clear and simple language. The children were included and underwent evaluation after their guardians agreed to and signed the informed consent. A total of 52 volunteer Brazilian children participated in the present study -24 boys and 28 girls, aged 6 to 11 years. - Table 1 shows the distribution of children who were involved, according to age and gender.

The inclusion criteria were as follows: children should be between 6 and 11 years old on the day of the proposed assessment; have hearing within the normal range expected for their age; have no difficulty in understanding the test administered; have no complaint and/or affliction of the upper airways on the day of the examination; and have no history of complaints regarding inattention and hyperactivity. The exclusion criteria were as follows: children with neurological and/or mental impairments; children with communication disorders; and children using medication for attention deficit hyperactivity disorder (ADHD).

To verify that the children included in the study did not present with any audiological alteration, an auditory screening was performed after a visual inspection of the external auditory canal. The auditory screening consisted of an evaluation of the response to air thresholds at frequencies of $500 \mathrm{~Hz}, 1,000 \mathrm{~Hz}$, and $2,000 \mathrm{~Hz}$, as well as tympanometry. Air tonal thresholds of up to $15 \mathrm{dBHL}$ and type A tympanometric curves ${ }^{12}$ were considered normal.

To verify the information related to health and auditory attention ability, a questionnaire was administered. The questionnaire consists of four parts: Part I - demographics of the children, including name, gender, age, address, educational level (all the children were in elementary school: 13 children in 1st grade; 11 in 2nd grade; 09 in 3rd grade; 09 in 4th grade; 04 in 5th grade; 04 in 6th grade; and, 01 in 7th grade), and education level of the parents ( 01 complete elementary school; 01 high school; and, 50 complete higher education); Part II - hearing health, history of hearing loss and ear infections (there was no history of hearing loss in children; 4 reports of an episode of bilateral ear infections and 1 report of bilateral ear microsurgery), and, if present, laterality; Part III - attention span of the child, especially not paying attention to instructions more than $50 \%$ of the time, needing instructions to be repeated frequently, asking what 
Chart 1 Comparison between the original and the new sustained auditory attention ability test software

\begin{tabular}{|l|l|l|}
\hline Features & Original SAAAT & SAAAT Software \\
\hline Format & Compact Disk - CD & Software \\
\hline Audio (test itself) & $\begin{array}{l}\text { Uninterrupted presentation } \\
\text { of a list of 100 words pre- } \\
\text { sented 6 times }\end{array}$ & $\begin{array}{l}\text { Uninterrupted presentation of a list of 100 words presented } \\
6 \text { times }\end{array}$ \\
\hline Stimulus rate & One word per second & One word per second \\
\hline Average test duration (audio) & 9 minutes & 9 minutes \\
\hline Response & $\begin{array}{l}\text { Raise your hand every time } \\
\text { you hear the word “no" }\end{array}$ & Clicking the mouse every time you hear the word “no" \\
\hline Record of responses & $\begin{array}{l}\text { Manual registration by the } \\
\text { evaluator in a specific } \\
\text { protocol }\end{array}$ & $\begin{array}{l}\text { Automatic registration by the system, visible on the } \\
\text { notebook screen }\end{array}$ \\
\hline Test result & $\begin{array}{l}\text { Evaluator counts errors and } \\
\text { scores the result }\end{array}$ & Automatic scoring by the system \\
\hline
\end{tabular}

Abbreviation: SAAAT, sustained auditory attention ability test.

was said, constantly saying "huh?" or "what?," showing a short attention span, not paying attention to sounds, exhibiting "daydreaming" behavior, having a diagnosis of ADHD and/or communication disorders, and use of medication for ADHD; and Part IV - school performance (one child had poor performance and another had school failure; two children had teacher complaints), repetition history, behavioral problems, inattention in the classroom, and complaints from teachers.

To evaluate the ability of sustained auditory attention, the assessment process consisted of the use of the SAAAT software developed in partnership with a graduate student studying systems analysis. The SAAAT software followed the original SAAAT model, ${ }^{8}$ with necessary updates (- Chart 1 shows comparisons between the two formats).

The SAAAT software was created using JAVA programming for language and for the execution environment, due to its security, portability, network resources, simplicity in specification, and free license. Additionally, MySQL was used for the database, due to its reliability, high performance, consistency, and ease of use. The SAAAT software presents the following information on screen, prior to beginning the evaluation: identification data, hearing health, child's attention, and school data. Once the audiological evaluation is completed, using a recording of audio files in the software, calculation of results and final report are presented. Similar to the original format, prior to presenting the word list, the SAAAT software has a calibration tone, which was adjusted to the level of intensity required for each ear of the child being assessed, using the volume units (VUs) meter of the twochannel audiometer. The recording of the audio file, which is the test itself, consisted of the uninterrupted presentation of a list of 100 Brazilian Portuguese words, repeated 6 times in a row. The words consisted of 21 monosyllables familiar to the child (não, pé, sim, flor, gol, trem, mar, sol, quer, mal, lã, boi, meu, sal, pai, gás, vou, céu, já, pó, and um), which were repeated and rearranged randomly, with one monosyllable presented every second. These files were recorded and equalized by professionals from the acoustic laboratory of a private company, aiming to harmonize the sounds. The software also contains an audio file including 50 monosyllables with 10 target words, which is used for training.

The test was only once the child demonstrated an understanding of the task during training. The child, seated in a chair inside the acoustic booth, was instructed orally by the evaluator as follows: the child would hear a list of many words, and should use the index finger of their dominant hand to click the left mouse button, which was attached to the arm of the chair on the dominant side, whenever they heard the word "no." Once the test was started, it would not stop until its completion.

The SAAAT software was installed on a Sony Vaio notebook, model PCG-6W3P (Sony Group Corp., Minato City, Tokyo, Japan), which was coupled to a two-channel audiometer, Midimate 622 (Madsen Eletronics Audiometer, GN Otometrics A/S, Copenhagen, Denmark). The audio recording was presented binaurally through supra-aural headphones, TDH 39, at an intensity of $50 \mathrm{dBNS}$, based on the average auditory air thresholds of $500,1,000$, and $2,000 \mathrm{~Hz}$ for each ear, and had an average total duration of 11 minutes.

To evaluate the child's performance, the total error score (sum of inattention and impulsivity scores) and the vigilance decrement were considered. Inattention was defined as any time when the child did not press the mouse button in response to the target word ("no") or pressed it before the next word was presented, and impulsivity was defined as any time when the child pressed the mouse button in response to any word other than the target word ("no").

The vigilance decrement was obtained by calculating the difference between the number of correct answers for the word "no" in the $1^{\text {st }}$ and $6^{\text {th }}$ presentations, to evaluate for any declination in attention during the vigilance task. Responses are automatically computed by the SAAAT software, and scores are calculated automatically as well; therefore, at the end of the test, it is possible to view the score for each parameter on the computer screen for each child. 
Table 2 Median and percentiles (25th-75th) for errors of inattention, errors of impulsivity, total error score, and vigilance decrement, based on gender

\begin{tabular}{|l|l|l|l|l|}
\hline Gender & Inattention & Impulsivity & Total score & Vigilance decrement \\
\hline Female & $47.5(32.0-70.8)$ & $47.5(27.8-60.0)$ & $94.0(61.5-136.0)$ & $3.50(1.0-5.25)$ \\
\hline Male & $33.0(20.3-48.0)$ & $30.5(17.5-49.5)$ & $68.0(37.8-97.5)$ & $3.00(1.0-5.00)$ \\
\hline$p$ & $0.023^{*}$ & $0.036^{*}$ & $0.021^{*}$ & 0.567 \\
\hline
\end{tabular}

Statistical test: Mann-Whitney test.

*- statistically significant difference $(p<0.05)$.

The performance of the children included in the present study were compared with the scores obtained in a survey including 280 children (139 girls and 141 boys), who were subjected to the same inclusion and exclusion criteria as those of the present study, and who were administered the SAAAT in its original format. ${ }^{8}$ The data were presented using mean and standard deviation for data, with normal distribution and median and percentiles for data with abnormal distribution. The Mann-Whitney test was used to compare the genders, and the Pearson correlation coefficient was used to evaluate the correlation between age and the scores obtained. In all tests, a $p$-level of $5 \%(p<0.05)$ was considered significant.

\section{Results}

The distribution of mean and standard deviation, inattention, impulsivity, total error score, and vigilance decrement for children based on gender and age are shown in - Tables 2 and 3, respectively. Statistically significant differences were found for errors of inattention, errors of impulsivity, and total error score in the comparison between genders, with females displaying a greater number of errors.
Analyzing the variable of age, the Pearson correlation coefficient ( - Table 4) shows a significant difference for inattention, impulsivity, and total error score, with all coefficients being negative, indicating that the number of errors decreases as age increases. The vigilance decrement, however, did not show a significant correlation with age.

\section{Discussion}

In the present study, sustained auditory attention was evaluated through the application of the SAAAT software and determined by the total error score (sum of inattention and impulsivity errors) and the vigilance decrement, as found in children without hearing complaints, attention disorders, or any current communication disorders.

Although previous studies ${ }^{8,13-16}$ have reported that age has a greater influence than gender on the performance of tasks of continuous performance, the results from the present study indicated statistically significant differences in the scores for inattention, impulsivity, and total errors when considering gender (-Table 2 ), indicating that females had more inattentive and impulsive errors than the males, seen as higher values and worse performance in the SAAAT

Table 3 Mean values (Xs) and standard deviations (SDs) for errors of inattention, errors of impulsivity, total error score, and vigilance decrement, based on age

\begin{tabular}{|l|l|l|l|l|}
\hline Age (years) & Inattention & Impulsivity & Total score & Vigilance decrement \\
\hline 6 & $63.6 \pm 24.7$ & $61.9 \pm 26.8$ & $125.5 \pm 50.9$ & $3.4 \pm 3.5$ \\
\hline 7 & $38.0 \pm 12.7$ & $35.6 \pm 11.1$ & $73.6 \pm 23.1$ & $3.6 \pm 3.5$ \\
\hline 8 & $45.3 \pm 26.1$ & $43.4 \pm 23.3$ & $88.7 \pm 48.5$ & $1.9 \pm 3.7$ \\
\hline 9 & $45.8 \pm 21.1$ & $36.0 \pm 18.0$ & $81.8 \pm 38.5$ & $3.3 \pm 3.3$ \\
\hline 10 & $30.0 \pm 26.2$ & $28.0 \pm 23.0$ & $58.0 \pm 49.1$ & $2.6 \pm 2.7$ \\
\hline 11 & $37.2 \pm 23.9$ & $37.4 \pm 29.4$ & $74.6 \pm 53.3$ & $3.6 \pm 3.5$ \\
\hline
\end{tabular}

Table 4 Correlation between age and errors of inattention, errors of impulsivity, total error score, and vigilance decrement

\begin{tabular}{|l|l|l|l|l|}
\hline Correlation with age & Inattention & Impulsivity & Total score & Vigilance decrement \\
\hline $\mathrm{r}$ & -0.28 & -0.31 & -0.30 & 0.05 \\
\hline $\mathrm{P}$ & $0.042^{*}$ & $0.024^{*}$ & $0.029^{*}$ & 0.722 \\
\hline
\end{tabular}

Statistical test: Pearson correlation coefficient.

*- statistically significant correlation $(p<0.05)$. 
software results. Although there are few behavioral differences between the genders in childhood, in relation to impulsivity the differences seem to emerge at the age of four, with boys showing more aggressive and impulsive behaviors, ${ }^{17}$ contrary to what was observed in the present study. Another previous study ${ }^{18}$ compared CPT performance between boys and girls with and without ADHD. Through a meta-analysis, they found a small, but significant difference between boys and girls with ADHD in commission errors (impulsivity), similar to that found between boys and girls without ADHD. Those results were in contrast with the difference found between boys with ADHD and boys of their control group, which was significantly greater than the differences between girls with ADHD and girls in the control group. Although the differences were similar between children with and without ADHD when accounting for gender, there is, potentially, a substantial discrepancy between gender-related differences. In children with ADHD, this finding is important, as it highlights a potential gender bias in the diagnosis of ADHD. The authors ${ }^{18}$ suggested that inhibitory control may be mediated by gender. The higher impulsivity scores ${ }^{19}$ may be explained by their earlier occurrence in girls. ${ }^{20}$ Difficulties related to inhibitory control are generally associated with impulsivity, seen as commission errors in tasks of continuous performance, when the subject responds to a stimulus that is not the specified target. $^{21}$ It is noteworthy that gender may have shown a significant difference due to the influence of age; however, it was not possible to perform the interaction of the two variables (gender and age) in the statistical analysis, due to the abnormal distribution of dependent variables in the analysis by gender.

The statistically significant difference observed in inattention, impulsivity, and total error scores based on age (-Tables 3 and $\mathbf{4}$ ) is in agreement with other studies, ${ }^{14,16}$ which have indicated that younger children make more mistakes than older ones. A weak negative correlation was observed between the items inattention, impulsivity, and total error score related to age ( - Table 4 ), indicating that younger children tend to commit more inattention and impulsivity errors and, consequently, have higher total error score than older children.

The absence of statistical significance in the other parameters assessed in the performance of the SAAAT software (-Tables 2, 3, and 4), particularly the vigilance decrement, with respect to both age and gender, demonstrates that the decline in attention that occurred during the vigilance task was similar for all children in the study. This finding is contrary to that observed in another study, ${ }^{6}$ which found higher vigilance decrement values for younger children.

When comparing the error scores found in the study (-Table 5), higher values were found when using the SAAAT software when compared with the original version. ${ }^{6,8}$ These scores, increased in errors of inattention and impulsivity and total error score, and decreased in vigilance ( - Tables 1 and 2), may reflect the children's reaction times in response to the previously determined stimulus, and the time allocated for the 1-second period between words, so that each answer was computed. Reaction time was defined as the time interval between the presentation of the stimulus and the appearance of a voluntary response, ${ }^{22}$ that is, the period of time between the beginning of the target stimulus and the beginning of a subject's motor response. ${ }^{23}$ This interval represents the level of muscle coordination at which the body, by means of different mechanical, chemical, and physical processes, decodes the visual or auditory stimuli, and reaches the brain as a sensory stimulus. ${ }^{24}$ Thus, the auditory stimuli-the words presented by the SAAAT software-were displayed every second. A correct response would entail the child pressing the mouse button within the time allocated while listening to the previously determined target word. Their answers were recorded and scored automatically by the system. If the response to the target word was executed after the allocated period of time, the response was considered an error. Specifically, it was computed as an inattention error since there was no response to the target word within one second, or as an impulsivity error, if the response occurred within a second of the following word, which was not the target word. Thus, having an insufficient time for the child to respond could justify the high number of inattention and impulsivity errors and, consequently, the total error score. In addition, researchers have reported that computer skills, level of motivation, mood, and understanding of instructions can influence the results of CPTs, which could, thus, also justify the higher scores seen with the SAAAT software. ${ }^{25}$

When comparing the values obtained in the vigilance decrement between the different test formats (original CD and software), it may be inferred that the tasks required by the SAAAT software were less motivating than those of the original version for children aged 7, 9, 10, and 11 years old, which showed a statistically significant, which showed a statistically significant difference when comparing the application of the tests in the two different formats (-Table 5), demonstrating greater mental fatigue than those aged 6 and 8 years, as mental fatigue can be seen as a progressive decrease in vigilance, exacerbated by the time spent on a tedious but demanding task. ${ }^{26}$

As a limitation of this study, we can mention the small sample of children in each age group, as well as the difference in the distribution of male and female children in each group, making it difficult to analyze some parameters.

\section{Conclusion}

The performance of girls who used the SAAAT software, which was developed to assess sustained auditory attention and vigilance, was worse than that of boys; except for vigilance decrement, younger children made more mistakes when using the SAAAT software; inattention errors were more frequent than impulsivity errors. Higher values were found when using the SAAAT software compared with the original version.

Before the widespread clinical use of this software, it is important to repeat this study with a more homogeneous sample, including new evaluation parameters in the 
Table 5 Comparison of the original sustained auditory attention ability test and the new software, in relation to age

\begin{tabular}{|c|c|c|c|c|}
\hline \multicolumn{5}{|c|}{ INATTENTION } \\
\hline AGE (years) & ORIGINAL & SOFTWARE & dif. & $p$ \\
\hline 6 & $27.3 \pm 14.2$ & $63.6 \pm 24.7$ & 36.24 & $<0.001^{*}$ \\
\hline 7 & $20.0 \pm 11.0$ & $38.0 \pm 12.7$ & 17.93 & $<0.001^{*}$ \\
\hline 8 & $17.0 \pm 11.7$ & $45.3 \pm 26.1$ & 28.21 & $<0.001^{*}$ \\
\hline 9 & $12.1 \pm 8.4$ & $45.8 \pm 21.1$ & 33.68 & $<0.001^{*}$ \\
\hline 10 & $9.7 \pm 7.6$ & $30.0 \pm 26.2$ & 20.26 & $<0.001^{*}$ \\
\hline 11 & $8.6 \pm 8.4$ & $37.2 \pm 23.9$ & 28.60 & $<0.001^{*}$ \\
\hline \multicolumn{5}{|l|}{ IMPULSIVITY } \\
\hline & ORIGINAL & SOFTWARE & dif. & $p$ \\
\hline 6 & $7.0 \pm 7.0$ & $61.9 \pm 26.8$ & 54.84 & $<0.001^{*}$ \\
\hline 7 & $4.6 \pm 3.3$ & $35.6 \pm 11.1$ & 30.98 & $<0.001^{*}$ \\
\hline 8 & $3.7 \pm 2.7$ & $43.4 \pm 23.3$ & 39.66 & $<0.001^{*}$ \\
\hline 9 & $4.5 \pm 6.2$ & $36.0 \pm 18.0$ & 31.48 & $<0.001^{*}$ \\
\hline 10 & $4.0 \pm 3.9$ & $28.0 \pm 23.0$ & 23.93 & $<0.001^{*}$ \\
\hline 11 & $2.4 \pm 2.2$ & $37.4 \pm 29.4$ & 34.93 & $<0.001^{*}$ \\
\hline \multicolumn{5}{|c|}{ TOTAL SCORE } \\
\hline & ORIGINAL & SOFTWARE & dif. & $p$ \\
\hline 6 & $34.4 \pm 15.0$ & $125.5 \pm 50.9$ & 91.0 & $<0.001^{*}$ \\
\hline 7 & $24.7 \pm 11.0$ & $73.6 \pm 23.1$ & 48.9 & $<0.001^{*}$ \\
\hline 8 & $20.8 \pm 12.0$ & $88.7 \pm 48.5$ & 67.8 & $<0.001^{*}$ \\
\hline 9 & $16.6 \pm 11.0$ & $81.8 \pm 38.5$ & 65.1 & $<0.001^{*}$ \\
\hline 10 & $13.8 \pm 9.9$ & $58.0 \pm 49.1$ & 44.2 & $<0.001^{*}$ \\
\hline 11 & $11.0 \pm 9.0$ & $74.6 \pm 53.3$ & 63.5 & $<0.001^{*}$ \\
\hline \multicolumn{5}{|c|}{ VIGILANCE DECREMENT } \\
\hline & ORIGINAL & SOFTWARE & dif. & $p$ \\
\hline 6 & $2.5 \pm 3.3$ & $3.4 \pm 3.5$ & 0.8 & 0.211 \\
\hline 7 & $1.5 \pm 2.6$ & $3.6 \pm 3.5$ & 2.1 & $0.001^{*}$ \\
\hline 8 & $1.7 \pm 2.6$ & $1.9 \pm 3.7$ & 0.1 & 0.864 \\
\hline 9 & $1.3 \pm 1.7$ & $3.3 \pm 3.3$ & 1.9 & $<0.001^{*}$ \\
\hline 10 & $1.0 \pm 2.2$ & $2.6 \pm 2.7$ & 1.5 & $0.002^{*}$ \\
\hline 11 & $1.3 \pm 1.8$ & $3.6 \pm 3.5$ & 2.3 & $<0.001^{*}$ \\
\hline
\end{tabular}

Statistical test: Student $t$-test.

*statistically significant difference $(p<0.05)$.

software, such as reaction time, the change in the stimulus rate of each word, and others, which were not available in this version. Additionally, there is a need to explore this software in various clinical settings and in populations with complaints and attention problems, including an assessment of sensitivity and specificity.

Conflict of Interests

The authors have no conflict of interests to declare.

Funding/Acknowledgment

Study with financial support from the National Research

Council (CNPq, in the Portuguese acronym).

\section{References}

1 Cohen RA. Focused and sustained attention. In: The Neuropsychology or Attention. SpringerNew York, NY, USA2014:89-112

2 Roebuck H, Freigang C, Barry JG. Continuous Performance Tasks: Not Just About Sustaining Attention. J Speech Lang Hear Res 2016; 59(03):501-510. Doi: 10.1044/2015_JSLHR-L-15-0068

3 Tremolada M, Taverna L, Bonichini S. Which Factors Influence Attentional Functions? Attention Assessed by KiTAP in 105 6-to10-Year-Old Children. Behav Sci (Basel) 2019;9(01):7. Doi: 10.3390/bs9010007

4 Krell J, Todd A, Dolecki PK. Bridging the Gap Between Theory and Practice in Neurofeedback Training for Attention. Mind Brain Educ 2019;13(04):246-260. Doi: 10.1111/mbe.12220

5 Jongman SR, Meyer AS, Roelofs A. The Role of Sustained Attention in the Production of Conjoined Noun Phrases: An Individual 
Differences Study. PLoS One 2015;10(09):e0137557. Doi: 10.1371/journal.pone.0137557

6 Ciria LF, Perakakis P, Luque-Casado A, Morato C, Sanabria D. The relationship between sustained attention and aerobic fitness in a group of young adults. PeerJ 2017;5:e3831. Doi: 10.7717/peerj.3831

7 Di Stasi LL, Diaz-Piedra C, Suárez J, et al. Task complexity modulates pilot electroencephalographic activity during real flights. Psychophysiology 2015;52(07):951-956. Doi: 10.1111/psyp.12419

8 Feniman MR, Ortelan RR, Lauris JRP, Campos CF, Cruz MS. A proposed behavioral tool to assess sustained auditory attention. Braz. J. Otorhinolaryngol 2007;73(04):523-527. Doi: 10.1590/ S0034-72992007000400011

9 Feniman MR, Rissatto ACS, Lauris JRP, Mondelli MFCG. Applicability of the free field Sustained Auditory Attention Ability Test (SAAAT). Int Arch Otorhinolaryngol 2012;16(02):269-277. Doi: 10.7162/S1809-97772012000200017

10 Mondelli MFCG, Carvalho FR, Feniman MR, Lauris JRP. Mild hearing loss: performance in the Sustained Auditory Attention Ability Test. Pro Fono 2010;22(03):245-250. Doi: 10.1590/S010456872010000300015

11 Lemos ICC, Feniman MR. Sustained Auditory Attention Ability Test (SAAAT) in seven-year-old children with cleft lip and palate. Rev Bras Otorrinolaringol (Engl Ed) 2010;76(02):199-205. Doi: 10.1590/S1808-86942010000200009

12 Jerger J. Clinical experience with impedance audiometry. Arch Otolaryngol 1970;92(04):311-324. Doi: 10.1001/archotol.1970.04310040005002

13 Hazin I, Falcão JTR, Garcia D, et al. Dados Normativos do Teste de Atenção por Cancelamento (TAC) em Estudantes do Ensino Fundamental. Psico: revista semestral do Instituto de Psicologia da PUC Rio Grande do Sul, Brasil 2012;43(04):428-436

14 Cortez R, Garcia DF, Maranhão S, et al. O desenvolvimento dos mecanismos atencionais em estudantes brasileiros do ensino fundamental. APL 2013;31(01):165-180

15 Rueda FJM, Monteiro RMM. Bateria psicológica para avaliação da atenção (BPA): desempenho de diferentes faixas etárias. Psico USF 2013;18(01):99-108
16 Coelho DG, Lima RF, Ims RE, Fonseca GUS, Ciasca SM. Desempenho de estudantes em instrumentos de atenção e funções executivas: análise do efeito da idade. Rev Sul-Am Psicol 2014;2 (02):214-239

17 Mahone EM, Schneider HE. Assessment of attention in preschoolers. Neuropsychol Rev 2012;22(04):361-383. Doi: 10.1007/s11065-012-9217-y

18 Hasson R, Fine JG. Gender differences among children with ADHD on continuous performance tests: a meta-analytic review. J Atten Disord 2012;16(03):190-198. Doi: 10.1177/1087054711427398

19 Groot AS, de Sonneville LM, Stins JF, Boomsma DI. Familial influences on sustained attention and inhibition in preschoolers. J Child Psychol Psychiatry 2004;45(02):306-314. Doi: 10.1111/ j.1469-7610.2004.00222.x

20 Greenberg LM, Waldman ID. Developmental normative data on the test of variables of attention (T.O.V.A.). J Child Psychol Psychiatry 1993;34(06):1019-1030

21 Malloy-Diniz LF, Paula de JJ, Sedó M, Fuentes D, Leite W. Neuropsicologia das funções executivas e da atenção. In: Fuentes D, Malloy-Diniz LF, Camargo CHP, Cosenza RM. Neuropsicologia - Teoria e Prátic [2ed.]. Porto Alegre: Artmed; 2014: 115-138

22 Jain AK. Manual of practical physiology for MBBS. 4th ed. New Delhi: Avichal Publishing Company; 2012:277-279

23 Bolfer C, Casella EB, Baldo MVC, et al. Reaction time assessment in children with ADHD. Arq Neuropsiquiatr 2010;68(02):282-286. Doi: 10.1590/S0004-282X2010000200025

24 Shelton J, Kumar GP. Comparison betwen Auditory and Visual Simple Reaction Times. Neurosci Med 2010;1(01):30-32. Doi: 10.4236/nm.2010.11004

25 Ogundele MO, Ayyash HF, Banerjee S. Role of computerised continuous performance task tests in ADHD. Progress in Neurology and Psychiatry 2011;15(03):8-13. Doi: 10.1002/pnp.198

26 Charbonnier S, Roy RN, Bonnet S, Campagne A. EEG index for control operators' mental fatigue monitoring using interactions between brain regions. Expert Syst Appl 2016;52:91-98. Doi: 10.1016/j.eswa.2016.01.013 